\title{
Revisiting the Sphere standards: comparing the revised Sphere standards to living standards in three urban informal settlements in Nairobi, Kenya
}

\author{
Ronak B. Patel ${ }^{1,2^{*}}$ (D) and Jay Chadhuri ${ }^{3}$
}

\begin{abstract}
Background: Humanitarian actors have long used the Sphere Handbook and its minimum standards to guide operational practice. The new revision attempts to update these standards partly to address urban crises that have challenged the humanitarian system. Yet, these indicators have never been based on a substantial body of evidence or data from the varied living standards found in cities or specifically informal settlements. This study aims to contextualize the Sphere standards for urban populations by comparing a sample of the revised key indicators to living standards in three urban informal settlements of Nairobi, Kenya, during a non-crisis period to examine their relevance and applicability, and discuss the implications.
\end{abstract}

Methods: Retrospective analysis of data sourced from randomized household surveys of three informal settlements in Nairobi across a range of living standards including a convenience sample of Sphere metrics is quantitatively compared to the newly revised Sphere standards.

Results: The results show that while some standards are met, many of the urban poor in these settlements live far below the prescribed minimum standards across many key sectors including water, sanitation, shelter, and food security. The data also reveal variations between and within individual informal settlements.

Conclusion: The Sphere standards are not informed enough by informality and remain largely aspirational for some populations and consensus rather than evidence-based. The revised handbook has made significant strides in highlighting the need for contextualization, market approaches, and incorporating stakeholder input. The new Sphere standards must be placed into context for use in the new urban agenda realigning humanitarian actions towards more locally contextualized and driven practice.

Keywords: Urban slum, Informal settlement, Sphere standards, Urban crises, Minimum standards, Localizing aid

\section{Background}

The Sphere Handbook, a cornerstone of humanitarian practice, recently underwent a major revision aiming to specifically address urban crises, which have challenged the humanitarian system (Sitko 2017). The handbook offers what it claims are universal minimum standards in

\footnotetext{
* Correspondence: rbpatel@gmail.com

'Department of Emergency Medicine, Harvard Medical School and Brigham and Women's Hospital, Boston, USA

2Director, Urbanization and Resilience Program, Harvard Humanitarian

Initiative, 75 Francis St., Boston, MA 02115, USA

Full list of author information is available at the end of the article
}

five sectors that dominate humanitarian relief efforts (water and sanitation, food aid, nutrition, health services, and shelter) (McConnan 2011; Darcy 2004). Key indicators and quantitative metrics accompany many of these minimum standards. The handbook has guided operations for decades and been used as a proxy to monitor and evaluate relief programs (Walker and Purdin 2004; Nickerson et al. 2015). It has played an important role in a field without standardized professionalization or training. When launched, the handbook was welcome and widely adopted as close to a standard of practice as 
possible. Yet the evidence base for many of these metrics is not well established (Blanchet et al. 2017). Their claimed universality also remains unsupported. The revision maintains that standards are universal and need only be contextualized. Notwithstanding, the utility of the Sphere standards and their relevance to complex urban situations remains questionable (Griekspoor and Collins 2001; Dufour et al. 2004).

Rapid urbanization has been well documented in the global south with city populations expanding at an extraordinary rate (Heilig 2012; Wang et al. 2012). With over $50 \%$ of the world's population now in urban areas, the Deputy Secretary General of the United Nations at the time remarked that the newly enacted Sustainable Development Goals would be won or lost in cities (UN Deputy Secretary-General Jan Eliasson 2015). Adequate housing, public infrastructure, and services have not expanded to keep pace with population growth, leading to large informal settlements throughout many of the fastest growing cities concentrating poverty with large variations, and deficiencies, in access to the key sectors identified in the Sphere Handbook (Birch and Wachter 2011; Habitat UN 2013; UN-Habitat 2004).

This rapid growth and deficiencies have undergone extensive debate within the literature presenting urban informality as a crisis. The development community has described rapid urbanization as a crisis for sustainable global development (Pieterse 2013). More specifically, the failures of municipal governments to keep pace has opened the door for non-traditional service providers for commonly public goods in informal settlements and beyond in rapidly growing cities with water as a basic example used to illustrate this as a crisis (Ranganathan 2014; Bakker 2010). In addition to the variations in basic goods and services relevant to the Sphere standards, urban complexity in its various manifestations has also challenged the humanitarian practice. Informality, not just the physical settlements that are a focus of this paper, but its multiple forms are not well incorporated into humanitarian practice (Twigg and Mosel 2018). Urban environments can a have a range of informal actors from community-based organizations to local gangs that have an impact on vulnerability to crisis (McFarlane and Waibel 2016). Additionally, informal sources of authority and legitimacy are present in complex urban environments with implications for how cities function (Recio 2013; Duminy 2011). These informalities must be acknowledged and navigated for successful humanitarian intervention but are often missing from response (Barcelo et al. 2011; Ramalingam et al. 2013). Along with the growth of informal settlements, police and justice deficits and the inability to perform the basic responsibilities of maintaining peace and even territorial control of these spaces have led to high rates of urban violence (Muggah 2013; N Moser 2004; Patel and Burkle 2012). These can often exceed violent death rates from declared conflicts and wars and have been referred to as a crisis as well that may necessitate a humanitarian response (Lucchi 2013). Finally, cities function as interconnected collections of systems and siloed approaches seem unfit for this level of complexity with new systems approaches being advocated for both urban disaster resilience and response (Campbell 2016; Da Silva et al. 2012). Accordingly, there are emerging tools to enable humanitarian practitioners to perform a more robust urban context analysis (Campbell 2018). The humanitarian community is actively reassessing existing tools and exploring new practice directly addressing cities and informal settlements (Meaux and Osofisan 2016; Ramalingam and Clarke 2012).

The urban focus for the Sphere Handbook revision reflects this overdue shift. Yet, determining appropriate standards in these varied settings will be contextual, based on the geography, climate, cultural norms, and other factors related to the baseline standard of living in each community. The second draft of the Sphere revision acknowledges this need to contextualize certain metrics (Sphere Project 2018). Yet, developing universal guidelines that allow a context-specific application seems to be a contradiction, and prescribing universal quantitative minimum values represents a challenge. Identifying universal minimum standards, if possible at all, requires a more granular understanding of the living standards in these cities. Understanding how populations live at baseline in these cities can better inform policy and practice. Unfortunately, there is a paucity of rigorous or representative data from urban slums on living conditions specific to the Sphere standards to guide an evidence-based revision and discussion of humanitarian metrics in urban areas (Klopp and Petretta 2017).

This study aims to place the newly revised Sphere standards in the context given the urban complexity and chronic crisis described above. A sample of Sphere metrics from living conditions in three informal settlements of Nairobi, Kenya during non-crisis periods are compared to the Sphere minimum standards for crisis-affected populations. Nairobi exemplifies rapid urbanization and informal settlement growth with over $60 \%$ of the city's residents living in slums (African Population and Health Research Center (APHRC) 2012). Urban growth in Africa has been treated to its own discussion as a threat to sustainable development and likened to an emerging crisis situation (Hove et al. 2013). Nairobi, however, has avoided significant acute crisis and serious humanitarian intervention relative to its neighbors in recent decades making it an ideal study site. Applying these Sphere standards to urban informal settlements presents a useful lens from which to analyze the concept of universal minimum standards in these environments, provide data to help interrogate the applicability of Sphere standards and open a discussion about the utility of Sphere standards in urban informal 
spaces specifically and emerging humanitarian practice that emphasizes locally contextualized and locally driven approaches adapted to an urban way of life overall.

\section{Methods}

\section{Site selection and rationale}

Several factors led to Nairobi as the selected areas for the Indicator Development for Slow Onset Urban Emergencies (IDSUE) study, from which this data was drawn. Concern Worldwide aimed to design an improved urban response framework based upon its experience responding to the Kenya 2008 post-election violence, where there was little evidence or triggers to inform timely and adequate humanitarian response. Humanitarian agencies and local government felt that existing thresholds to trigger humanitarian response were not designed for the most vulnerable informal settlements. Viwandani, Korogocho, and Mukuru have vulnerable populations which also have large populations. Chronic violence was endemic in most areas of these informal settlements. Tailoring new IDSUE indicators to account for chronic violence was a major consideration in site selection.

Korogocho, Viwandani, and Mukuru were selected as the initial sites for the study. Over the course of the IDSUE study, other informal settlements were selected for data collection. However, most were not revisited for future data collection. Korogocho, Mukue, and Viwandani had higher levels of vulnerability as well as large populations, justifying repeated data collection over several years.

A long-term grant provided the opportunity to emphasize local contexts by co-designing a questionnaire and set of indicators. The set of indicators were refined and reduced over a period of time.

\section{Sampling}

Collection of an accurate and representative sample in the informal settlements has several challenges. The most vulnerable areas of these informal settlements have continuous construction and destruction of settlement structures and significant movement of households. There are no updated census enumeration area or accurate estimation of households for any given village (the sub-unit of informal settlement). Therefore, a representative sample of households required a new and updated household listing before every round of data collection. The sampling design was repeated cross-sectional samples.

Boundaries of informal settlements are not official and are often disputed. For this study, local government boundaries were used as a starting point and then adapted based on consultation and inputs from local communities. Each village was split into segments where household listings which were used to generate a random sample. Sample sizes were calculated to ensure representation for each informal settlement (with 95\% confidence and 5\% margin of error).

\section{Data collection and analysis}

IDSUE data collection consisted of household surveys conducted at the doorstep of the randomly selected households in the Nairobi informal settlements by trained local staff. Many of the trained enumerators came from informal settlements. Data collection was conducted 3-4 times per year from August 2012 until February 2014. Data analyzed in this paper is from the round of data collection in February 2014 (A surveillance data collection system continues to this day in cooperation with Kenya Red Cross and Nairobi County n.d.).

In February 2014, a total of 2114 self-identified head of households (across all three settlements) responded to the questionnaire. Field-workers collected the data on mobile phones through a standardized interviewer-administered survey. Data collectors were overseen and trained by project leaders that also determined the sampling frame, organized the logistics, and reviewed the quality of data gathered. Inclusion in the survey required residency in the slum (defined as continuous occupancy for more than 3 months) and consent by the head of household $(\mathrm{HoH})$ or representative of $\mathrm{HoH}$.

Focus group discussions and pilot surveys informed the final IDSUE questionnaire. IDSUE survey data collection used Open Data Kit (An open source software primarily used for mobile phone data collection n.d.). Data was analyzed using $\mathrm{R}$, an open source statistical language used for quantitative analysis and statistical computing (R Version 3.5.1 n.d.).

\section{Ethical review}

Consent was obtained from the self-identified $\mathrm{HoH}$ or their representative of all included households using an approved standardized consent form. Ethical review for the overall project and consent form approval was obtained from the Kenya Medical Research Institute (KEMRI) national ethical review committee. Stanford University Internal Review Board approved the data analysis for this manuscript with protocol IRB-37404.

\section{Findings}

Sphere minimum standards do not apply in all contexts. As illustrated in the following sections, many vulnerable informal settlements live below current Sphere standards. Two notable examples are the liters of water consumed per person and those indicators for food security. In addition, IDSUE data demonstrates a number of Sphere indicators that are inadequate when applied to urban informal settlements. Coping strategies (which Sphere has as an indicator of food security) and chronic violence (these specific types of insecurity indicators are 
excluded from Sphere). Shelter and non-food items are two Sphere domain areas which are not covered here, as they do not overlap with IDSUE data.

Demographic data of the three settlements vary and are summarized in Tables 1 and 2. Each of the three informal settlements also illustrates different vulnerabilities. Korogocho and Mukuru show a higher proportion of female-headed households, a vulnerable subgroup due to lower earnings, and a single income source. Households in Korogocho tend to reside there longer on average. Lower-income residents of Korogocho also have much lower incomes than Mukuru and Viwandani (Table 3).

Applying Sphere standards to these demographic data also illustrate the inadequacy of the standards to informal settlements. Korogocho falls well below the Sphere recommended shelter standard for the population density of $45 \mathrm{~m}^{2} /$ person with $21.2 \mathrm{~m}^{2} /$ person. Mukuru and Viwandani are above the standard.

\section{Water}

Quantitative Sphere indicators for water encompass the quantity, accessibility, and quality of the water. The data from these three informal settlements reveal the gap with regard to Sphere standards.

The indicator for water supply remains $15 \mathrm{l}$ of water per person per day $(\mathrm{L} / \mathrm{p} / \mathrm{d})$ for drinking, cooking, personal hygiene, and domestic hygiene. This is admittedly based on expert opinion and the handbook appropriately notes that this should be adjusted in each context. While the mean usage in each settlement exceeds the $15 \mathrm{~L} / \mathrm{p} / \mathrm{d}$ metric, this is misleading due to the wide-ranging inequality. The metric on how many actually meet the minimum quantity per person per day reveals how large quantity users skew this mean for the settlement. Looking closer, almost half of all households in these informal settlements, ranging from $46 \%$ in 2012 down to $40 \%$ in 2014, failed to meet the $15 \mathrm{l} /$ person/day standard. Table 4 also shows the variance in water consumption across informal settlements. The considerable variance across informal settlements illustrates the substantial number of households who are well below the minimum standard of $15 \mathrm{l} /$ person/day.

Sphere standards also require that public water points are "sufficiently close" to households, no more than 500 $\mathrm{m}$. These informal settlements meet this standard with

Table 1 IDSUE demographic information

\begin{tabular}{llll}
\hline & Korogocho & Mukuru & Viwandani \\
\hline Sample size & 705 & 705 & 704 \\
Avg household size (all ages) & 4 & 3 & 3 \\
Avg length of residency & 12 & 5 & 8 \\
Average age of head of household & 39 & 31 & 33 \\
Percent female heads of households & 31 & 29 & 17 \\
\hline
\end{tabular}

Table 2 Official population statistics of study sites

\begin{tabular}{llll}
\hline & Korogocho & Mukuru & Viwandani \\
\hline Population & 10,376 & 130,401 & 44,881 \\
Area (km2) & 0.22 & 8.11 & 5.71 \\
Population density (m2/p) & 21.2 & 62.2 & 127.2 \\
Households & 3129 & 49,198 & 17,926 \\
Female (\%) & 48 & 45 & 42 \\
Median & 8000 & 12,000 & 12,000
\end{tabular}

Source: 2009 Kenya National Population and Housing Census, Kenya National Bureau of Statistics

households less than an average 3 min to walk to a water source. Converting $3 \mathrm{~min}$ into the average comfortable pedestrian walking speed of $1.4 \mathrm{~m} / \mathrm{s}$ would only be a distance of $252 \mathrm{~m}$, well within the Sphere standard (Carey 2005).

The Sphere standards also indicate that wait times should not exceed $30 \mathrm{~min}$ at a queue to access water. Households in all three settlements all report times below this threshold.

Sphere standards also indicate that water should be "palatable and of sufficient quality to be drunk and used for cooking and personal and domestic hygiene without causing risk to health." While most meet this standard, many do not and reported quality varies significantly from settlement to settlement and within each settlement.

Sixty-five percent of residents in Korogocho, Mukuru, and Viwandani said they were satisfied with water facilities, and that they were adequate for water collection, storage, bathing, laundry, hand-washing, and laundry. Five percent were more than satisfied, with 30\% responding unsatisfied (Table 5).

\section{Sanitation}

The informal settlements under observation also fall short of Sphere standards with respect to excreta disposal. The revised Sphere minimum standards require that living environments of disaster-affected individuals are free from human fecal contamination, especially in homes, food production areas, public centers, and near water sources.

The presence of stool in open-areas is a vector-risk for a local population. Seventy-nine.(61\%) of respondents

Table 3 Average income for each quintile by area

\begin{tabular}{llll}
\hline & Korogocho & Viwandani & Mukuru \\
\hline Quintile 1 (1-20\%) & 5000 & 8000 & 8000 \\
Quintile 2 (21-40\%) & 6000 & 10,000 & 10,000 \\
Quintile 3 (41-60\%) & 9000 & 15,000 & 15,000 \\
Quintile 4 (61-80\%) & 13,000 & 20,000 & 20,000 \\
Quintile 5 (81-100\%) & 40,000 & 81,000 & 60,000 \\
\hline
\end{tabular}

Source: IDSUE February 2014. Note: February 2, 2014: 1 USD $=86.50$ Kenyan Schillings 
Table 4 Indicators which measure Sphere water standards

\begin{tabular}{llllll}
\hline & August 2012 & February 2013 & April 2013 & November 2013 & February 2014 \\
\hline $\begin{array}{l}\text { Proportion of households meeting 15 L of water/person/day } \\
\text { Sphere standard }\end{array}$ & 54 & 59 & 50 & 60 & 60 \\
\begin{tabular}{l} 
Prevalence of illness in the last 2 weeks (\%) \\
\hline
\end{tabular} & 43 & 43 & 43 & 42 & 47 \\
\hline
\end{tabular}

Source: IDSUE February 2014. All areas: Korogocho, Viwandani, Mukuru

said they noticed human feces in the local environment. Appropriate toilet facilities are integral to reducing fecal contamination in living environments and the standards require "All affected populations have adequate, appropriate, and acceptable toilet facilities, sufficiently close to their dwellings, to allow rapid, safe and secure access at all times." Given that the majority of the population shares a toilet and that large percentages in each settlement pay to use a toilet facility, there are clear concerns about whether this arrangement can constitute rapid, safe, and secure access at all times if the closest and safest facilities are either in use or affordability limits some from being able to use them. With these specific limitations in mind, they would seem to fail the requirements for adequacy, appropriateness, and acceptability (Table 6).

Distance to the facility was measured in minutes with $75 \%$ of households taking $10 \mathrm{~min}$ or less. Almost every household used a designated toilet facility though the type of facility varied by the settlement. Across all three settlements, only $1 \%$ of households, in Korogocho, report using no toilet facility at all and the majority there used a simple latrine. In contrast, improved facilities such as Ecosan toilets and flush toilets are used by the majority of residents in Mukuru and Viwandani.

Revised Sphere indicators suggest that $100 \%$ of people have appropriate, accessible, and safe toilets in public spaces and $100 \%$ of women and girls are satisfied with the menstrual hygiene opportunities. The Sphere guidelines recommend gender-segregated sanitation facilities as one way of achieving this. In the IDSUE survey, $91.86 \%$ of all respondents said there were no female-only toilets in the informal settlements, far short of meeting such targets.

\section{Solid waste management}

Sphere standards aim to ensure that $100 \%$ of households have "access to designated neighborhood or communal collection points at an acceptable (preferably pre-defined) distance from their dwellings and that all solid waste is safely and securely reused, recycled, composted, disposed of, or otherwise treated."

Over one third of households in these settlements did not have a designated waste disposal site or service. An average of $35 \%$ of households report disposing of their household waste on a road, railway, trench, or "all over."

The average distance, in minutes, to the nearest dumpsite was $6.98 \mathrm{~min}$. Assuming an average walking speed of $0.1 \mathrm{~km} / \mathrm{min}$, the average walk is almost $700 \mathrm{~m}$ to a dumpsite (Table 7).

\section{Food security}

Data from the 2014 IDSUE survey suggests that Nairobi's informal settlements do not meet the standards for food security.

Table 5 Accessibility and quality of water for informal settlement residents: price, source, and quality of water

\begin{tabular}{|c|c|c|c|}
\hline & Korogocho & Mukuru & Viwandani \\
\hline Pay for water (\%) & 89 & 99 & 96 \\
\hline Average time to walk to water source (min) & $2.6(2.11)$ & $2.43(2.04)$ & $2.4(2.10)$ \\
\hline Liters of water/person/day & $17.6(8.46)$ & $21.6(17.5)$ & $20.3(19.5)$ \\
\hline Meeting $15 \mathrm{~L} /$ day threshold (\%) & 58.86 & 67.92 & 55.09 \\
\hline \multicolumn{4}{|l|}{ Main water source (\%) } \\
\hline Piped or tap water & 95 & 95 & 81 \\
\hline Water tanks & 3 & 5 & 19 \\
\hline Water vendors & 2 & 0 & 0 \\
\hline Lake, river, or well & 0 & 0 & 0 \\
\hline \multicolumn{4}{|l|}{ Quality of water (\%) } \\
\hline Clean water & 86 & 69 & 74 \\
\hline Very clean water & 10 & 1 & 14 \\
\hline Dirty water & 4 & 29 & 11 \\
\hline Very dirty water & 0 & 1 & 1 \\
\hline
\end{tabular}

Source: IDSUE February 2014. Standard deviations in parenthesis 
Table 6 Toilet facilities and usage

\begin{tabular}{llll}
\hline & Korogocho & Mukuru & Viwandani \\
\hline Pay to use toilet facility (\%) & 18 & 48 & 74 \\
Share toilet facility (\%) & 95 & 98 & 98 \\
Main toilet facility (\%) & & & \\
Ecosan & 1 & 28 & 20 \\
Flush toilet & 10 & 29 & 77 \\
None & 1 & 0 & 0 \\
Other & 0 & 0 & 0 \\
Simple latrine & 83 & 38 & 2 \\
VIP latrine & 5 & 5 & 1 \\
\hline
\end{tabular}

Source: IDSUE February 2014

While Mukuru and Viwandani have demonstrated comparable rates of food security, there appears to be more inequality in food security for households within Viwandani. Households in Viwandani fell into the two extremes of "never" ate smaller meals (45\% of households) and "often" ate smaller meals (15\%) at higher rates than households in Mukuru. Across settlements, an average of $15 \%$ of families reported having no food "sometimes" or "often" given lack of household resources. On average, 7\% of households reported going an entire day and night without food sometimes or often. This food insecurity is experienced more in Korogocho than in Mukuru and Viwandani. Household Food Insecurity and Access (HFIAS) and Household Hunger Score (HHS) are two common food security indicators routinely monitored by humanitarian agencies with clear and standardized methods of calculation (Coates et al. 2007; Ballard et al. 2011).

MUAC is an indicator which is closely tracked by humanitarians. While rates for severe malnutrition are below $1 \%$, there are large populations which are at risk (Table 8).

\section{Coping strategies}

In the revised Sphere guidance, Coping Strategy Index (CSI) is one suggested indicator to monitor for food security. CSI as a global standard can overlook the monitoring of local contexts and emerging coping tactics within communities. For IDSUE, a different approach was taken. A range of coping strategies was tested with

Table 7 Garbage disposal practices

\begin{tabular}{llll}
\hline Garbage disposal practices (\%) & Korogocho & Mukuru & Viwandani \\
\hline Disposal service & 53 & 30 & 57 \\
Road/railway/trench/all over & 36 & 31 & 38 \\
Garbage dump or pit & 10 & 37 & 5 \\
Burning & 1 & 1 & 0
\end{tabular}

Source: IDSUE February 2014 local communities in order to determine anyhow households in the informal settlements dealt with a shock, reduction/loss of income, or upticks in localized chronic violence. These coping strategies are designed and tailored for Korogocho, Mukuru, and Viwandani, and are not intended to be a universal tool. For example, in Nairobi, consuming street foods is seen as a common coping strategy for vulnerable households (Table 9). These street foods are of a much lower quality and cost households less money than preparing a meal at home. The availability or prevalence of this tactic will not be the same in other urban informal settlements.

Ten indicators were selected (all are listed in Table 10) and can help humanitarian organizations and local government assess how households were dealing with shocks and inform any potential response. The majority of households in Korogocho, Mukuru, and Viwandani responded to using at least one coping mechanism in the past 4 weeks (Table 10). Negative coping strategies, such as taking children out of school or stealing to support the household, were more prevalent in Korogocho.

The IDSUE approach illustrates how indicators tailored to local contexts take into account nuances for coping as well as designing better response.

\section{Discussion}

These data reveal that, on average, residents in these informal settlements of Nairobi live, at baseline, below many critical Sphere minimum standards set for crisis-affected populations. This gap has implications for rethinking the concept of universal quantitative standards, adapting to local contexts, the utility of qualitative standards, and what constitutes a crisis.

The conventional observation of urbanization and its relationship with poverty emphasizes the dichotomy of slum versus non-slum areas. These data, however, highlight the diversity between and within the same settlements. This granular view is crucial for prioritizing the most vulnerable and supports the need for more localized approaches such as area-based programming. The distinction between a city's slum and non-slum areas may be more obvious, but this dichotomy disguises the range of vulnerabilities that exist among residents of informal settlements and the variations in their needs. Attention to indicators of human security, such as incomes, food security, and perceptions of safety render differences between informal settlements more apparent. While this study does not explore these topics to add nuance to these metrics, they illustrate the need for deep contextual knowledge of living environments for humanitarians that will increasingly engage the complexity of cities described in the introduction to effectively target resources and be effective. 
Table 8 Categories for child malnutrition (under 5)

\begin{tabular}{llll}
\hline MUAC for children 6 to 59 months old $(\%)$ & Korogocho & Mukuru & Viwandani \\
\hline Severe malnutrition $(<115 \mathrm{~mm})$ & 0.2 & 0.6 & 0.3 \\
Moderate malnutrition $(<125 \mathrm{~mm})$ & 1.9 & 1.2 & 1.2 \\
At risk for malnutrition $(<135 \mathrm{~mm})$ & 9.5 & 6.5 & 9.5 \\
\hline
\end{tabular}

Source: IDSUE February 2014

Notably, while a large percentage of these populations do not meet Sphere minimum metrics for water consumption and use, most reported that the quantity and quality of water meet their basic needs. This tension presents a dilemma for designing minimum standards and what it means when populations have adapted to living below these international standards. Science cannot dictate what is acceptable to meeting needs as this will vary by all the uses water may serve for an individual and their household depending on how they live in the city rather than a simplified camp model. Person's subjective ideas of "meeting needs" would also determine how satisfied they are with the quality and quantity of water provided. The new revision makes mention of this and the need to estimate higher daily water needs for wealthier populations within urban areas, but having minimum indicators seems another contradiction. While science may dictate a human's need for water consumption to sustain life, even these will also vary by climate, daily activities, and even individual. Developing minimum quantitative indicators for water is questionable when addressing this complexity.

This study also highlights the role of markets and interconnected urban systems such as infrastructure and transportation in meeting basic water standards set by the humanitarian community. While water prices remained

Table 9 Food security indicators (February 2014)

\begin{tabular}{llll}
\hline All areas & Korogocho & Mukuru & Viwandani \\
\hline Consumed street foods (\%) & 57 & 31 & 36 \\
Adult & 54 & 26 & 33 \\
Child (under 18 years old) & 11 & 6 & 5 \\
Household Food Insecurity and Access (HFIA) & & \\
HFIA score (HFIAS) & 9 & 24 & 32 \\
Food secure (\%) & 4 & 19 & 15 \\
Mildly food insecure (\%) & 23 & 24 & 24 \\
Moderately food insecure (\%) & 65 & 34 & 29 \\
Severely food insecure (\%) & & & \\
Household hunger & 1.4 & 0.8 & 0.5 \\
Household Hunger Score (HHS) & 57 & 78 & 87 \\
Little to no hunger (\%) & 37 & 18 & 10 \\
Moderate household hunger (\%) & 37 & 4 & 4 \\
Severe household hunger (\%) & 6 &
\end{tabular}

Source: IDSUE February 2014 constant and stable during the data collection, the ability for price gouging or price inflation in times of water scarcity or acute crises is highly probable. Although wait times for water are likely to increase with any supply disruptions as a result of any disaster, there are a number of options for people to access to water (tanks, local vendors, municipal service). Urban infrastructure such as water pipes and roads for tankers represent a critical element for meeting water needs for residents of Nairobi's informal settlements. Price gouging by vendors can be a greater concern for many urban dwellers.

Multiple studies show that food security has similarly strong connections with the market in urban areas and there is a growing trend in urban humanitarian practice to incorporate cash- and market-based approaches also noted in the draft Sphere revision. More research is needed to develop such approaches and link them to standards.

This points to a common concern where potential risks in access to basic goods and services for slum-dwellers are linked to urban systems and market uncertainties post-disaster.

Understanding the urban context and how people meet their needs to live their lives is critical. Urban response frameworks should consider the dynamics of an informal settlement and the city at large. Markets, municipal policies, informal power brokers, interconnected urban systems, and complex networks of public and private providers along with adaptations by local populations themselves determine the standard of living for the urban poor. Humanitarian practice must begin to recognize and address these levers rather than simply set quantitative and qualitative norms that seem divorced from realities on the ground lest they lose their utility.

There is a promising opportunity that aligns well with the new Sphere recommendation of understanding coping strategies and contextualization. Assessing vulnerability based on coping strategies could represent a way forward. Yet, these indicators must also be contextualized. Broader coping strategies from commonly used global indicators were not always relevant for this study. Rather a tailored approach, with co-design of the questionnaire with the community, was employed.

Beyond this, these data suggest a role for development and humanitarian actors along with local authorities to coordinate on such standards to contextualize and refine 
Table 10 Localized coping strategies used by households to deal with shocks (percentage of households in the previous 4 weeks)

\begin{tabular}{llll}
\hline $\begin{array}{l}\text { Percentages of households who } \\
\text { reported yes to the following: }\end{array}$ & Korogocho & Mukuru & Viwandani \\
\hline Used credit & 57 & 47 & 32 \\
Took a loan & 16 & 27 & 11 \\
Removed children from school & 38 & 25 & 20 \\
Household member left household & 8 & 8 & 8 \\
Begged for food or money & 8 & 7 & 4 \\
Stolen food or money & 0.6 & 0.9 & 0.4 \\
Know someone that stole & 26 & 8 & 13 \\
Got food/money from friend/family/ & 43 & 35 & 29 \\
neighbor & & & \\
Taken a second job & 29 & 31 & 22 \\
Sold an asset & 13 & 16 & 7 \\
Used one or more of the above & 84 & 72 & 59 \\
\hline
\end{tabular}

Source: IDSUE February 2014

aid response. More far-reaching, the data possibly challenge humanitarian actors to consider redefining target populations or mandates as growing urban poverty chronically places individuals in situations well below minimum humanitarian standards.

These findings fall into a line of prior work that has questioned the utility of Sphere standards. Prior work has reviewed the missing areas for urban contexts specifically identifying gaps in standards and metrics (Janneck et al. 2011). Critiques have discussed its potential relevance only to ideal camp settings while creating unrealistic expectations for post-disaster recovery and failing to address underlying factors for vulnerability (Griekspoor and Collins 2001). Further work has questioned how sustainable they may be for local actors to take forward and pursue (Pinera and Bosher 2011). Similarly, protracted crises with a mix of acute relief and recovery operations may find them unfit to guide service delivery (McDougal and Beard 2011). Others have focused less on the applicability of metrics and evidence base behind them, moving directly to a rights-based approach using the humanitarian charter as a basis to address these complex scenarios (Young et al. 2004; Ouyang et al. 2009; Ali and Kabau 2014). A human rights-based approach may in fact lead to appropriate qualitative standards as others have argued. But operationalizing qualitative standards without specific indicators or metrics can be challenging at best and futile at worst. Engaging local populations in the process of developing relevant standards specific to their context offers a promising alternative. Nonetheless, all of these critiques apply to the complexity of the urban landscape and, like this study, suggest a need for local contextualization. Indeed, humanitarian practice that adopts such approaches such as area-based programming.
Developing quantitative universal minimum standards for a single city after a crisis seems challenging. The lack of evidence to support these metrics is obviated by their seeming irrelevance in informal settlements. Standards, indicators, and metrics all have a purpose, but these rapidly growing cities with existing populations living in such varied conditions are not easily addressed, nor are they meant to be, by humanitarian interventions alone. While the concept of these quantitative metrics made sense for camps that were designed and run by aid agencies, they seem unfit for urban crises. Engaging local populations in the process of developing relevant standards specific to their context offers a promising alternative. Beyond this, these data suggest a role for development and humanitarian actors along with local authorities and communities to coordinate on standards to contextualize and refine development and humanitarian aid response that mirrors emerging locally driven practice.

There are limitations to interpreting these data that stem from studying a dynamic population as well as the methodology employed. The data presented here are snapshots and vary over time. This variation does not undercut the significance of the findings that at any given time, large proportions of the population in these settlements live well below Sphere minimum standards at baseline. Additionally, only a sample of the Sphere standards are compared here and do not reflect the overall quality of life compared to these minimum standards yet they represent some basic standards. Not only are the data a sample of the Sphere standards, but the three slums themselves are also only a sample of the communities in Nairobi and not necessarily representative of Nairobi slums or generalizable beyond Nairobi. While these limitations of representativeness and generalizability remain true, they underscore the point that rapidly growing cities represent collections of microenvironments and the variation among them challenges the idea of "universal" standards. As a sample of communities, they call for more granular data of urban environments and living standards that can inform the discussion on humanitarian standards and operations.

This study presents the most rigorous evaluation of the Sphere indicators for urban informal settlement populations. A population estimated at well over a billion persons and rising. With the majority of the world's population now living in cities, humanitarian operations will increasingly target urban populations. New research with more granular and spatially disaggregated data as well as more open and honest evaluation of current practices and standards driven by evidence is needed. This study opens the door to such a discussion. 


\section{Acknowledgements}

The authors would like to acknowledge all of the leadership and effort by Concern Worlwdie and it staff as well as the local partners and volunteers including the local data collectors that helped devise and collect the dataset used for this manuscript.

\section{Role of the funding source}

OFDA did not have a role in study design or methods of data collection, analysis or interpretation of data. All authors had full access to the data and have final responsibility for the decision to submit for publication.

\section{Funding}

The study employs a dataset from the Indicator Development for Surveillance of Urban Emergencies (IDSUE) project executed by Concern Worldwide and funded by the United States Agency for International Development (USAID) Office of Foreign Disaster Assistance (OFDA). The datasets used in this paper are from the rounds operated solely by Concern Worldwide.

\section{Availability of data and materials}

Please contact author for data requests.

\section{Authors' contributions}

Both authors conceptualized the investigation. RBP drafted the initial objectives and introduction. Both authors determined the analyses to perform. JC drafted the initial methodology and performed the data analyses. Both authors equally interrogated the analysis and drafted the results and discussion sections. Both authors edited and finalized the manuscript for publication. Both authors read and approved the final manuscript.

\section{Competing interests}

The authors declare that they have no competing interests.

\section{Publisher's Note}

Springer Nature remains neutral with regard to jurisdictional claims in published maps and institutional affiliations.

\section{Author details}

'Department of Emergency Medicine, Harvard Medical School and Brigham and Women's Hospital, Boston, USA. 'Director, Urbanization and Resilience Program, Harvard Humanitarian Initiative, 75 Francis St., Boston, MA 02115, USA. ${ }^{3}$ New York, USA.

Received: 19 September 2018 Accepted: 4 March 2019

Published online: 12 March 2019

\section{References}

African Population and Health Research Center (APHRC) (2012) Population and Health Dynamics in Nairobi's Informal Settlements: Report of the Nairobi Cross-sectional Slums Survey (NCSS). APHRC, Nairobi

Ali S, Kabau T (2014) Non-state actors and the evolution of humanitarian norms $J$ Int Humanit Legal Stud 5(1-2):70-104

An open source software primarily used for mobile phone data collection: https://opendatakit.org/

Bakker K (2010) Privatizing water: governance failure and the world's urban water crisis. Cornell University Press, Ithaca

Ballard T, Coates J, Swindale A, Deitchler M (2011) Household hunger scale: indicator definition and measurement guide. Food and Nutrition Technical Assistance (FANTA), Washington $p 2$

Barcelo J, Masaud A, Davies A (2011) Meeting humanitarian challenges in urban areas: review of urban humanitarian challenges in Port-au-Prince, Manila, Nairobi, Eldoret. UN Habitat, Nairobi Available from: www.urban-response. org/help-library/meeting-humanitarian-challenges-in-urban-areas-review-ofurban-humanitarian-challenges

Birch EL, Wachter SM (eds) (2011) Global urbanization. University of Pennsylvania Press, Philadelpha

Blanchet K, Severine F, Smith J (2017) Review of evidence supporting the Sphere standards. Enhanced Learning and Research for Humanitarian Assistance (ELRHA) Available from http://www.elrha.org/wp-content/uploads/2017/03/ Evidence-Review-Sphere-LSHTM-March-2017_FINALw-intro.pdf
Campbell L (2016) Stepping back: understanding cities and their systems. ALNAP working paper. ALNAP/ODI, London Available from: https://www. preparecenter.org/sites/default/files/alnap-urban-systems-stakeholders-2016web.pdf

Campbell L (2018) What's missing? Adding context to the urban response toolbox. ALNAP Study. ALNAP/ODI, London Available from: https:/www.alnap.org/ system/files/content/resource/files/main/Whats\%20Missing_ Adding\%20context\%20to\%20the\%20urban\%20response\%20toolbox_Digital.pdf

Carey N (2005) Establishing pedestrian walking speeds. Portland State University Available from: https://www.westernite.org/datacollectionfund/2005/psu_ ped_summary.pdf

Coates J, Swindale A, Bilinsky P (2007) Household Food Insecurity Access Scale (HFIAS) for measurement of food access: indicator guide. Food and Nutrition Technical Assistance Project, Academy for Educational Development, Washington, DC, p 34

Da Silva J, Kernaghan S, Luque A (2012) A systems approach to meeting the challenges of urban climate change. Int J Urban Sustain Dev 4(2):125-145

Darcy J (2004) Locating responsibility: the sphere humanitarian charter and its rationale. Disasters 28(2):112-123

Dufour C, Geoffroy V, Maury H, Grünewald F (2004) Rights, standards and quality in a complex humanitarian space: is Sphere the right tool? Disasters 28(2): $124-141$

Duminy J (2011) Literature survey: informality and planning. University of Cape Town Available from: http://www.inclusivecities.org/wp-content/uploads/ 2012/07/Duminy-Planning-Lit-Review_FINAL.pdf

Griekspoor A, Collins S (2001) Raising standards in emergency relief: how useful are Sphere minimum standards for humanitarian assistance? BMJ 323(7315): 740

Habitat UN (2013) State of the world's cities 2012/2013: prosperity of cities. Routledge, Nairobi

Heilig GK (2012) World urbanization prospects: the 2011 revision. United Nations, Department of Economic and Social Affairs (DESA), Population Division. Population Estimates and Projections Section, New York

Hove M, Ngwerume ET, Muchemwa C (2013) The urban crisis in Sub-Saharan Africa: A threat to human security and sustainable development. Stability 2(1):7

Janneck LM, Patel R, Rouhani SA, Burkle FM (2011) Urbanization and Humanitarian Access Working Group: toward guidelines for humanitarian standards and operations in urban settings. Prehosp Disaster Med 26(6): 464-469

Klopp JM, Petretta DL (2017) The urban sustainable development goal: indicators, complexity and the politics of measuring cities. Cities 63:92-97

Lucchi E (2013) Humanitarian interventions in situations of urban violence. ALNAP Lessons Paper. ALNAP/Overseas Development Institute, London

McConnan I. Humanitarian charter and minimum standards in disaster response. $<$ The> Sphere Project; 2011, SBN 978-1-908176-00-4.

McDougal L, Beard J (2011) Revisiting Sphere: new standards of service delivery for new trends in protracted displacement. Disasters 35(1):87-101

McFarlane C, Waibel M (2016) Introduction: the informal-formal divide in context in McFarlane and Waibel (eds) Urban Informalities: reflections on the formal and informal. Routledge, London

Meaux A, Osofisan W. A review of context analysis tools for urban humanitarian response. 2016. Available from: https://www.preparecenter.org/sites/default/ files/urban_context_analysis_tools_10797iied.pdf.

Muggah R (2013) Researching the urban dilemma: urbanization, poverty and violence. International Research Development Centre, 2013 Available from: https://idl-bnc-idrc.dspacedirect.org/bitstream/handle/10625/53538/IDL53538.pdf? sequence=1\&isAllowed $=y$

N Moser CO (2004) Urban violence and insecurity: an introductory roadmap. Environ Urban 16(2):3-16

Nickerson JW, Hatcher-Roberts J, Adams O, Attaran A, Tugwell P (2015) Assessments of health services availability in humanitarian emergencies: a review of assessments in Haiti and Sudan using a health systems approach. Confl Heal 9(1):20

Ouyang H, VanRooyen M, Gruskin S (2009) The sphere project: next steps in moving toward a rights-based approach to humanitarian assistance. Prehosp Disaster Med 24(3):147-152

Patel RB, Burkle FM (2012) Rapid urbanization and the growing threat of violence and conflict: a 21st century crisis. Prehosp Disaster Med 27(2):194-197

Pieterse DE (2013) City futures: confronting the crisis of urban development. Zed Books Ltd., New York 
Pinera JF, Bosher L (2011) Sphere and sustainability : a matter of time. J Humanit Assist. Available at: https://dspace.lboro.ac.uk/dspacejspui/bitstream/2134/ 7929/1/Sphere\%20and\%20sustainability\%27\%20\%282011\%29\%20by\% 20Pinera\%20and\%20Bosher\%20.pdf

R Version 3.5.1. R Foundation for Statistical Computing, https://www.r-project.org/ Ramalingam B, Clarke PK (2012) Meeting the urban challenge: adapting humanitarian efforts to an urban world. In: Meeting the Urban Challenge: Adapting Humanitarian Efforts to an Urban World Active Learning Network for Accountability and Performance in Humanitarian Action (ALNAP)

Ramalingam B, Gray B, Cerruti G (2013) Missed opportunities: the case for strengthening national and local partnership-based humanitarian responses. ActionAid, CAFOD, Christian Aid, Oxfam GB and Tearfund, London Available from: www.alnap.org/help-library/missed-opportunities-the-case-forstrengthening-national-and-local-partnership-based

Ranganathan M (2014) "Mafias" in the waterscape: urban informality and everyday public authority in Bangalore. Water Altern 7(1):89-105

Recio R (2013) Engaging the "ungovernable": urban informality issues and insights for planning. J Urban Reg Plann 2(1):18-37

Sitko P (2017) Humanitarian response is getting a major urban overhaul. Citiscope Available from: http://citiscope.org/commentary/2017/05/ humanitarian\%2D\%2Dgetting-major-urban-overhaul

Sphere Project, Sphere Handbook 2018. 2018. Available from: https:/ spherestandards.org/handbook-2018/

Twigg J, Mosel (2018) Informality in urban crisis response, working paper 532. Overseas Development Institute, London Available at: https://www.odi.org/ sites/odi.org.uk/files/resource-documents/12065.pdf

UN Deputy Secretary-General Jan Eliasson. Battle for Sustainable Development Will Be Won or Lost in Cities, Deputy Secretary-General Tells Mayor's Forum. 2015. Press Release. DSG/SM/874-HAB/229. Available from: https://www.un. org/press/en/2015/dsgsm874.doc.htm.

UN-Habitat (2004) The challenge of slums: global report on human settlements 2003. Manag Environ Qual 15(3):337-338

Walker P, Purdin S (2004) Birthing sphere. Disasters 28(2):100-111

Wang H, He Q, Liu X, Zhuang Y, Hong S (2012) Global urbanization research from 1991 to 2009: a systematic research review. Landsc Urban Plan 104(3-4):299309

Young H, Taylor A, Way SA, Leaning J (2004) Linking rights and standards: the process of developing 'rights-based' minimum standards on food security, nutrition and food aid. Disasters 28(2):142-159

\section{Submit your manuscript to a SpringerOpen ${ }^{\circ}$ journal and benefit from:}

- Convenient online submission

- Rigorous peer review

- Open access: articles freely available online

- High visibility within the field

- Retaining the copyright to your article

Submit your next manuscript at $\boldsymbol{\nabla}$ springeropen.com 